\title{
Levodopa-Induced Dyskinesia: Facts and Fancy. What Does the MPTP Monkey Model Tell Us?
}

\author{
Paul J. Bédard, Baltazar Gomez Mancilla, Pierre Blanchette, Céline Gagnon and Thérèse Di Paolo
}

\begin{abstract}
Levodopa-induced dyskinesia, one of the most frequent long-term side effects of antiparkinsonian therapy, is often attributed to denervation supersensitivity of dopamine receptors and perhaps more specifically the D-1 receptor. The available evidence based not only on clinico-pathological studies in patients but also on results of experiments performed on methyl-phenyl-tetrahydropyridine (MPTP)-treated monkeys suggests that the mechanisms may be more complex than heretofore believed. Thus it appears that no single receptor is the sole culprit, that some form of denervation supersensitivity is probably involved but not in the form of increased density of dopamine receptors. Moreover, other neurotransmitter systems must be considered such as GABA, excitatory aminoacids and peptides. The MPTP monkey model remains very useful for predicting the potential of new drugs for inducing dyskinesia. Such trials however must be performed in drug-naive animals.
\end{abstract}

RÉSUMÉ: Dyskinésies induites par la lévodopa: faits et mythes que nous enseigne le modèle du singe traité par le MPTP? Les dyskinésies induites par la lévodopa, un des effets secondaires à long terme les plus fréquents de la thérapie antiparkinsonienne, sont souvent attribuées à une hypersensibilité de dénervation des récepteurs dopaminergiques et peut-être plus spécifiquement du récepteur D-1. Les données disponibles, basées non seulement sur des études clinico-pathologiques chez des patients, mais aussi sur les résultats d'expériences effectuées chez les singes traités par le MPTP, suggèrent que les mécanismes peuvent être plus complexes que nous ne le croyons antérieurement. Ainsi, il ne semble pas que le responsable soit un seul récepteur. Une certaine forme d'hypersensibilité de dénervation est probablement impliquée, mais par sous la forme d'une augmentation de la densité des récepteurs dopaminergiques. De plus, d'autres systèmes de neurotransmetteurs doivent être considérés, tels le système GABA, les acides aminés excitateurs et les peptides. Le modèle des singes triatés au MPTP demeure très utile pour prédire le potentiel de nouveaux médicaments à induire des dyskinésies. Cependant, de tels essais doivent être effectués chez des animaux naïfs.

Can. J. Neurol. Sci. 1992; 19: 134-137

\section{What Does Clinical Experience Teach Us?}

Since the first descriptions of this common side effect ${ }^{1.2}$ many important observations have been made which may give us leads as to the pathophysiology of dyskinesia. Dyskinesia may be of different types: dystonic, choreic, myoclonic, ballic and may occur at the peak of the effect of levodopa or towards the beginning and/or end of the effect. For the purpose of the present discussion, we will limit ourselves to the most frequent form of dyskinesia which is choreic or choreoathetoid in nature and occurs at the peak of the motor effect, often being inseparable from the therapeutic action. It occurs in 30 to $80 \%$ of patients treated with levodopa. In our own sample of 117 patients the prevalence was found to be $42 \%$.

Dyskinesias are a result of substantial loss of the dopaminergic nigrostriatal pathway. In fact they appear sooner in patients with severe denervation such as those in whom the syndrome was induced by MPTP. ${ }^{3}$ Moreover they almost always appear on the side where the parkinsonian signs first appeared, that is the most denervated side. These facts would therefore suggest that the denervation process plays an important role in their development.

In severely affected patients dyskinesias generally appear after months of treatment, although in some instances they are seen after a few days. However they are never seen after a single dose of levodopa. Their incidence is lower in groups of patients who are treated with lower doses of levodopa and in patients treated instead with dopamine agonists. ${ }^{4-6}$ This would suggest the treatment itself plays a priming role. Once dyskinesias have appeared, they seem to become progressively more severe, despite a constant dose and they can be attenuated by reducing the dose of levodopa at the cost of increased disability.

From the Centre de recherche en neurobiologie (P.J.B., B.G.M., P.B.) et Département des Sciences neurologiques (P.J.B., P.B.), Hôpital de I'EnfantJésus Centre de recherche en endocrinologie moléculaire, Centre Hospitalier de l'Université Laval (C.G., T.D.P.); Département de Pharmacologie, Faculté de Médecine (P.J.B., B.G.M., P.B.) et École de Pharmacie (C.G., T.D.P), Université Laval

Reprint requests to: P.J. Bédard, Centre de recherche en neurobiologie, Hôpital de l'Enfant-Jésus, 1401, 18e Rue, Québec, Québec, Canada GIJ IZ4 
It is our impression that the intensity is dose-dependent although this is disputed by certain authors. ${ }^{8}$

One of the most interesting pharmacological clues that we have is the fact the patients treated from the beginning with the dopamine D-2 agonist bromocriptine instead of levodopa develop remarkably less dyskinesia and fluctuations after a few years. ${ }^{4-}$ ${ }^{7}$ This is also true for patients treated with a combination of levodopa and bromocriptine. ${ }^{7}$ This would suggest that the therapeutic benefit of replacement therapy is somehow linked to the D-2 receptor while dyskinesia would be linked to the other type: the D-1 receptor.

In summary, these observations when put together would suggest that under conditions of denervation, the striatum (or another structure) reacts in an abnormal fashion to repetitive stimulation of the D-1 receptor and that this leads to dyskinesia. If true, treatment with selective D-2 agonists should provide relief without dyskinesia. Moreover since the processes of denervation and the repetitive interaction of the drug with the receptors both seem to play a role, if we could learn to control and understand these processes, we might be able to avoid these side-effects.

The development of the MPTP monkey model ${ }^{9-14}$ has provided us with an invaluable tool to test these hypotheses and study the effect of new selective agents in a paradigm that allows definite conclusions: single drug therapy under controlled conditions in drug-naive animals followed by histochemical, electrophysiological and eventually biochemical analysis of the brain.11.15-18 We will thus review some of the statements often heard concerning dyskinesia and what answers can be provided by pharmacological studies in the MPTP model.

\section{Fact or Fancy? Dyskinesia is Due to Denervation Supersensitivity of Dopamine Receptors}

Several studies have shown that dopamine D-2 receptors are increased in density in the striatum of parkinsonian patients not currently undergoing treatment. ${ }^{21-23}$ Some of these studies ${ }^{21,23}$ have shown however that treatment with levodopa reverses this increase so that if denervation supersensitivity is defined as an increased density of receptors it would be maximal before treatment and tend to be reduced by treatment, which is not compatible with the appearance and progressive increase in dyskinesia during treatment.

Increases in D-1 receptor binding in Parkinson's disease have also been observed. ${ }^{24-26}$ Interestingly, according to Rinne et al., ${ }^{25}$ this was especially true in patients treated with levodopa and displaying dyskinesia.

In the MPTP monkey model, nigrostriatal damage is required for induction of dyskinesia. ${ }^{14,27}$ We have also observed increases in both D-2 (with $\left[{ }^{3} \mathrm{H}\right]$ spiperone) ${ }^{18.19}$ and D-1 receptors (with $\left.\left[{ }^{3} \mathrm{H}\right] \mathrm{SCH}-23390\right)^{28}$ following treatment with MPTP. However in both cases, the upregulation was reversed by treatment with LDopa or dopamine agonists in animals who had developed prominent dyskinesia.

This would seem to minimize the role of denervation supersensitivity. However, in more recent work (unpublished) using both antagonist and agonist ligands for the D-2 and D-1 receptors, we have seen that in the striatum of MPTP monkeys D-2 binding to both the antagonist and agonist is increased maximally in the more posterior regions, but that chronic treatment with dopamine agonists reverses both. In the case of $D-1$ receptors, denervation is followed by increased binding to the antagonist in the posterior regions but decreased binding to the agonist, indicating a shift to the low affinity state. Chronic treatment with dopamine agonists reverses this situation so that there is a shift to the high affinity state of the D-1 receptor.

Moreover the study of receptors in extrastriatal regions has disclosed some very interesting observations. For instance in the substantia nigra and internal globus pallidus, denervation is followed by no change or increased total binding to $\left[{ }^{3} \mathrm{H}\right] \mathrm{SCH}$ 23390 but a shift to decreased binding to the agonist $\left[{ }^{3} \mathrm{H}\right]$ SKF38393. Thus although we do not yet have the total picture of changes in dopamine receptors, we must pay attention not only to the density but to the affinity of dopamine receptors for the agonist. We must also pay more attention to extra striatal output structures which are rich in dopamine (D-1) receptors such as the globus pallidus and substantia nigra pars reticulata. Interestingly Robertson and Robertson ${ }^{29}$ believe that a large part of the action of L-Dopa is exerted on D-1 receptors in these output structures. Moreover Parent $\&$ Smith $^{30}$ have identified a direct nigropallidal (internal division) dopaminergic pathway which seems more resistant to MPTP. ${ }^{31}$

The concept of denervation supersensitivity could also be broadened to include synapses placed downstream from the dopaminergic receptors. For instance changes in activity of striatal output cells can affect GABAergic transmission in the globus pallidus. Robertson et al. ${ }^{32}$ have reported that MPTP. induced parkinsonism is accompanied by decreased $\left[{ }^{3} \mathrm{H}\right]$ flunetrazepam binding in the external division of the globus pallidus.

\section{Fact or Fancy? Dyskinesia is the Result of Stimulation of D-1 Receptors}

As mentioned above, the fact that bromocriptine is less likely to induce dyskinesia would seem to support this conclusion. If true, selective D-1 agonists should induce prominent dyskinesia with little therapeutic benefit while D-2 agonists should do the opposite. It would thus appear logical to develop selective and potent D-2 agonists. In a recent study Boyce et al. ${ }^{33}$ report that the powerful D-2 agonist (+)-PHNO administered to monkeys who had already developed dyskinesia on L-Dopa does not reproduce the same dyskinesia. We have recently performed similar experiments and found that in our hands all D-2 agonists tried on animals who had developed dyskinesia on L-Dopa reproduced the same movements. These included Quinpirole $0.1-0.5 \mathrm{mg} / \mathrm{kg}$, (+)-PHNO $(2-10 \mu \mathrm{g} / \mathrm{kg})$, bromocriptine $5 \mathrm{mg} / \mathrm{kg}$, Terguride and RU-24213.

On the other hand the D-1 agonist SKF-38393, 5-15 mg/kg as reported earlier ${ }^{18.19 .34 .35}$ had no motor effect and did not reproduce the L-Dopa induced dyskinesia. Another D- 1 agonist CY$2082243^{36}$ was also tried but at a dose of $0.1 \mathrm{mg} / \mathrm{kg}$ produced a locomotor activation without dyskinesia while at $0.5 \mathrm{mg} / \mathrm{kg}$ (a dose which may not be selective) it also produced dyskinetic movements.

The effect of the D-2 agonists was blocked selectively by the D-2 antagonist sulpiride while that of CY-208243 was antagonized selectively by $\mathrm{SCH}-23390,0.05 \mathrm{mg} / \mathrm{kg}$.

Thus, these results do not support an exclusive link between dyskinesia and the D-1 receptor on one hand and the motor response and the D-2 receptor on the other hand. Our results would rather suggest that the D-2 receptor is more important for both aspects of the motor response. 
These results were obtained in animals who had already developed dyskinesia with L-Dopa. As mentioned above, LDopa seems to exert a priming effect on dyskinesia. Once primed, the animals will respond to most dopamine agonists by dyskinetic movements even after two months without treatment (unpublished results). Interestingly this also includes bromocriptine, a drug which appears less likely to induce priming by itself in humans $\mathrm{s}^{4-7}$ or monkeys. ${ }^{11,18,19}$ It is therefore possible that the process of "priming" is different from the capacity to elicit dyskinesia once the animal has been primed with levodopa.

We have therefore treated groups of MPTP monkeys who had received no levodopa or dopamine agonists with a single selective agent. Among D-2 agonists, (+)-PHNO $(6 \mu \mathrm{g} / \mathrm{kg}$ daily) and quinpirole $(0.5 \mathrm{mg} / \mathrm{kg}$ daily) induced typical choreoathetoid dyskinesia of the limbs within a week, which is faster than with L-Dopa (3-4 weeks). Bromocriptine $(5 \mathrm{mg} / \mathrm{kg}$ ) induced none even after six weeks. Neither did the D-1 agonist SKF-38393. However the D-1 agonist CY-208243, $0.5 \mathrm{mg} / \mathrm{kg}$ induced typical choreothetoid and dystonic movements after two weeks. These results indicate that at the very least the priming effect cannot be attributed solely to the D-1 receptor.

The fact that bromocriptine is capable of producing a locomotor response without dyskinesia must be explained by other peculiarities of this drug, such as its long half life, the fact that is has some D-I antagonist properties or the fact that it does not discriminate between the high and low affinity state of the D-2 receptor. ${ }^{37}$

\section{Fact or Fancy? Partial Agonists Would be Less Likely to Induce Dyskinesia}

A partial agonist is usually defined as a drug which, while reproducing the effects of the neurotransmitter, is incapable of producing the maximum effect, and reduce the efficacy of the neurotransmitter or of "full" agonists. In the field of antiparkinsonian agents, the term has often been used to describe agents which seem to have no effect on receptors which are in the low affinity state. Thus, drugs such as -3-PPP or Terguride have little effect on postsynaptic D-2 dopamine receptors under normal conditions but are effective only under conditions of denervation when the receptors are apparently shifted to the high affinity state. Since these agonists interact with a subpopulation of D-2 receptors it was hoped that they might have motor effects without side effects such as dyskinesia.

Unfortunately, in recent experiments involving monkeys which had already developed dyskinesia with L-Dopa we have shown that both Terguride and -3-PPP not only produce locomotor stimulation but elicit the same dyskinesia as L-Dopa. This does not however rule out the possibility that such agents if they were given de novo to parkinsonian patients or MPTP monkeys who have not been exposed to levodopa would not have the "priming" effect and would not elicit dyskinesia.

\section{Fact or Fancy? The Type of Dyskinesia is Related to the Type of Drug or Receptor}

In a recent report, Boyce et al. ${ }^{33}$ have observed that, at the dose given and in their population of MPTP monkeys, the D-2 agonists (+)-PHNO did not reproduce exactly the same dyskinesia as levodopa. More specifically the abnormal movements tended to be more dystonic while levodopa induced movements of a choreic nature. In recent experiments, we have observed in a group of MPTP animals rendered dyskinetic with L-Dopa that animals who had movements mostly of choreic nature had exactly the same movements with several D-2 agonists ((+)PHNO, bromocriptine, Terguride, Quinpirole, RU-24213) and the D-1 receptor agonist CY-208243. On the other hand, animals who had mostly dystonic movements had the same movements with either the D-2 or the D-1 agonists. Moreover, when groups of naive MPTP monkeys were treated with selective D-2 (Quinpirole, (+)-PHNO) or D-1 (CY-208243) agonists a majority of animals in both groups developed choreoathetoid movements but a subgroup had mostly dystonic movements irrespective of the type of receptor involved. We thus conclude that the type of movements has more to do with the motor "personality" of the animal than with the type of drug or receptor.

Fact or Fancy? Testing a New Drug in MPTP Monkeys Will Help Predict Whether it Will Induce Abnormal Movements in Patients

This statement is partly true. Most studies published to date, ${ }^{12.27}$ including some of our own, involve animals who had received levodopa or other agonists and had already developed dyskinesia. Under such conditions the answer is still useful in the sense that it tells us whether switching a dyskinetic patient over to that agent will solve his problem. However we have not yet encountered an agent which could under such conditions induce a locomotor response without dyskinesia except perhaps the D-1 agonist CY-208243 at a low dose $(0.1 \mathrm{mg} / \mathrm{kg})$. It is noteworthy that even bromocriptine which we know elicits few dyskinesias when given de novo to patients ${ }^{4-7}$ or monkeys ${ }^{11.18 .19}$ will reproduce very nicely levodopa-induced dyskinesia under such conditions.

To know whether an agent is capable of inducing the change in the CNS that leads to dyskinesia (priming) one must use MPTP monkeys which have never received even one dose of levodopa or other agonists, as we do not know how much exposure is necessary for the "priming" effect. It is also preferable to wait two months after MPTP-treatment since limb dyskinesia are easier to elicit in this period than immediately after MPTP. A positive response can occur after a few days with potent agonists such as (+)-PHNO but for other drugs it may be necessary to treat the animals daily for a least a month and still a negative response does not entirely rule out that a larger dose or a longer exposure to this particular agent would eventually elicit dyskinesia.

In conclusion, we believe that the MPTP monkey is a useful tool to screen new potential antiparkinsonian agents for their propensity to induce dyskinesia, since up to now the response of the MPTP monkey to such agents has proven remarkably similar to that of humans. Perhaps more importantly however, this model may allow us to understand the mechanism of such side effects since it is possible to study single agents under more rigorous scientific conditions than is possible in patients. Moreover, we now have access to knowledge of the firing pattern of the structures of the basal ganglia during dyskinesia ${ }^{16}$ as well as to the changes in various receptors ${ }^{11.18 .19}$ neurotransmitters $^{17}$ and peptides ${ }^{15}$ after treatment.

\section{ACKNOWLEDGEMENT}

Supported by MRC of Canada and Parkinson Foundation of Canada 


\section{REFERENCES}

1. Barbeau A. L-dopa therapy in Parkinson's disease: a critical review of nine years' experience. Can Med Assoc J 1969; 101: 791-800.

2. Cotzias GC, Van Woert MH, Schiffer LM. Aromatic amino acids and modification of parkinsonism. N Engl J Med 1967; 276: 374-379.

3. Langston WJ, Ballard P. Parkinsonism induced by 1-methyl-4phenyl-1,2,3,6-tetrahydropyridine (MPTP): implications for treatment and the pathogenesis of Parkinson's disease. Can J Neurol Sci 1984; 11: 160-165.

4. Lees AJ, Stern GM. Sustained bromocriptine therapy in previously untreated patients with Parkinson's disease. J Neurol Neurosurg Psychiatry 1981; 44: 1020-1023.

5. Rascol A, Guiraud B, Montrastruc JL, et al. Long-term treatment of Parkinson's disease with bromocriptine. J Neurol Neurosurg Psychiatry 1979; 42: 143.

6. Rinne UK, Combined bromocriptine-levodopa therapy early in Parkinson's disease. Neurology 1985; 35: 1196-1198.

7. Rinne UK. Early combination of bromocriptine and levodopa in the treatment of Parkinson's disease: a 5 year follow-up. Neurology 1987; 37: 826

8. Nutt JG. Levodopa-induced dyskinesia. Neurology 1990; 40: 340345.

9. Burns RS, Chiueh CC, Markey SP, et al. A primate model of parkinsonism: selective destruction of dopaminergic neurones in the pars compacta of the substantia nigra by 1-methyl-4-phenyl1,2,3,6-tetrahydropyridine. Proc Natl Ácad Sci U.S.A. 1983; 80 4546-4550.

10. Langston J, Forno LS, Robert CS, et al. Selective nigral toxicity after systemic administration of MPTP in the squirrel monkey. Brain Res 1984; 292: 390-394.

11. Bédard PJ, Di Paolo T, Falardeau P, et al. Chronic treatment with $\mathrm{L}$-dopa, but not bromocriptine induces dyskinesia in MPTPparkinsonian monkeys: correlation with $\left[{ }^{3} \mathrm{H}\right]$ spiperone binding. Brain Res 1986: 379: 294-299.

12. Clarke CE, Boyce S, Robertson RG, et al. Drug-induced dyskinesia in primates rendered hemiparkinsonian by intracarotid administration of 1-methyl-4-phenyl-1,2,3,6-tetrahydropyridine (MPTP) J Neurol Sci 1989; 90: 307-314.

13. Jenner P, Rupniak NMJ, Rose S, et al. 1-Methyl-4-phenyl-1,2,3,6tetrahydropyridine-induced parkinsonism in the common marmoset. Neurosci Lett 1984; 51: 47-53.

14. Schneider JS. Levodopa-induced dyskinesia in parkinsonian monkeys: relationship to extent of nigrostriatal damage. Pharmacol Biochem Behav 1989; 34: 193-196.

15. Lavoie B, Parent A, Bédard PJ. Effect of dopamine denervation on striatal peptide expression in parkinsonian monkeys. Can J Neurol Sci (in press).

16. Tremblay $L$, Filion $M$, Responses of pallidal neurons to striatal stimulation in intact waking monkeys. Brain Res 1989; 498: 1. 16.

17. Di Paolo T, Bédard PJ, Daigle M, et al. Long-term effects of MPTP on central and peripheral catecholamine and indoleamine concentrations in monkeys. Brain Res 1986; 379: 286.

18. Falardeau P, Bouchard S, Bédard PJ, et al. Behavioural and biochemical effect of chronic treatment with D1 and/or D2 dopamine agonists in MPTP monkeys. Eur J Pharmacol 1988; 150: $59-66$.

19. Falardeau P, Bédard PJ, Di Paolo T. Relation between brain dopamine loss and D2 dopamine receptor density in MPTP monkeys. Neurosci Lett 1988; 86: 225-229.
20. Rouillard C, Bédard PJ, Di Paolo T. Behavioral and biochemical effect of chronic treatment of MPTP-monkeys with bromocriptine alone or in combination with SKF-38393. Eur J Pharmacol 1990; 185: 209-215.

21. Lee T, Seeman P, Rajput A, et al. Receptor basis for dopaminergic supersensitivity in Parkinson's disease. Nature (Lond) 1978; 273: 59-61.

22. Bokobza B, Ruberg M, Scatton B, et al. ( $\left.{ }^{3} \mathrm{H}\right)$ Spiperone binding, dopamine and HVA concentrations in Parkinson's disease and supranuclear palsy. Eur J Pharmacol 1984; 99: 167-175.

23. Guttman M, Seeman P. L-Dopa reverses the elevated density of D2 dopamine receptors in Parkinson's diseased striatum. J Neural Transm 1985; 64: 93-104.

24. Raisman R, Cash R, Ruberg M, et al. Binding of $\left({ }^{3} \mathrm{H}\right)-\mathrm{SCH} 23390$ to Dl receptors in the putamen of control and parkinsonian subjects. Eur J Pharmacol 1985; 113: 467-468.

25. Rinne JO, Rinne JK, Laakso K, et al. Dopamine DI receptors in the parkinsonian brain. Brain Res 1985; 359: 306-310.

26. Seeman P, Bzowej NH, Guan HC, et al. Human brain D1 and D2 dopamine receptors in Schizophrenia, Alzheimer's, Parkinson s and Huntington's diseases. Neuropsycopharmacology 1987; 1: 5-15.

27. Boyce S, Rupniak NMJ, Steventon MJ, et al. Nigrostriatal damage is required for induction of dyskinesias by L-Dopa in squirrel monkeys. Clin Neuropharmacol 1990; 13:448-458.

28. Gagnon C, Bédard PJ, Di Paolo T. Effect of chronic treatment of MPTP monkeys with dopamine D-1 and/or D-2 receptor agonists. Eur J Pharmacol 1990; 178: 115-120.

29. Robertson GS, Robertson HA. D1 and D2 dopamine agonist synergism: separate sites of action. Trends Pharmacol Sci 1987; 8: 295-299.

30. Parent A, Smith Y. Differential dopaminergic innervation of the two pallidal segments in the squirrel monkey (Saimiri Sciurcus). Brain Res 1986: 426: 397-400.

31. Parent A, Lavoie B, Smith Y, et al. The dopaminergic nigropallidal projection in primates: distinct cellular origin and relative sparing in MPTP-treated monkeys. In: Streifler MB, Korczyn A, Melamed E., Youdim MBH, eds. Advances in Neurology. New York: Raven Press, 1990; 53: 111-116.

32. Robertson RG, Clarke CA, Boyce $S$, et al. The role of striopallidal neurones utilizing gamma-aminobutyric acid in the pathophysiology of MPTP-induced parkinsonism in the primate: evidence from $\left[{ }^{3} \mathrm{H}\right]$ flunitrazepam autoradiography. Brain Res 1990; 531: 95-104.

33. Boyce S, Rupniak NMJ, Steventon MJ, et al. Differential effects of D1 and D2 agonists in MPTP-treated primates. Neurology 1990; 40: $927-934$

34. Close SP, Marriott AS, Pay S. Failure of SKF-38393-A to relieve parkinsonian symptoms induced by MPTP in the marmoset. $\mathrm{Br} \mathrm{J}$ Pharmacol 1985; $85: 320-322$.

35. Nomoto $M$, Jenner $P$, Marsden $C D$. The dopamine D-2 agonist LY131865 but not the D-1 agonist SKF-38393 reverses parkinsonism induced by 1-methyl-4-phenyl-1,2,3,6-tetrahydropyridine (MPTP) in the common marmoset. Neurosci Lett 1985; 57 : 37 41.

36. Markstein R, Seilers MP, Vigault JM, et al. Pharmacological properties of CY-208243 a novel D1 agonist. In: Sandler, M. Dahlstrom A, Belkmaker RH, eds. Progress in catecholamine research Part B. New York: Alan R. Liss, 1988.

37. Jackson DM, Jenkins OF, Ross SB. The motor effects of bromocriptine: a review. Psychopharmacology 1988; 95: 433446 